\title{
Do discurso e de sua análise: reflexões sobre limites e possibilidades na Ciência da Administração
}

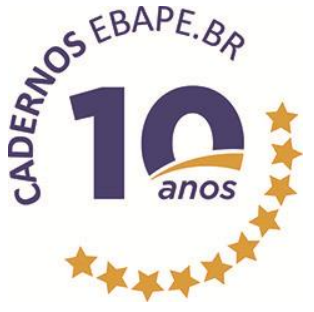

\section{On discourse and its analysis: reflections about limits and possibilities in Administration Science}

\author{
Marcio Silva Rodrigues ${ }^{1}$ \\ Eloise Helena Livramento Dellagnelo ${ }^{2}$
}

\begin{abstract}
Resumo
Considerando que tanto o discurso da empresa como o discurso científico (paradigma dominante) constituem-se, atualmente, em um veículo de manifestação/legitimação direta da ideologia vigente, seja para convencer, impor ou estabelecer acordos sobre o indivíduo, neste trabalho discutimos as características, os usos e as possibilidades da análise do discurso como uma proposta teórica e metodológica que, além de desnudar a crença em um único sentido, em uma única verdade, forneça meios que possibilitem promover tanto teorias e práticas distantes do modelo hegemônico como, principalmente, (re)construir sentidos e práticas, em todos os aspectos da vida humana envolvida, que estejam, de certa maneira, livres das pressões e do discurso e da ideologia vigente. Para concretizar essa proposta, primeiramente, apresentamos as noções gerais sobre discurso e análise do discurso, em seguida, abordamos as características de duas correntes da análise do discurso, a corrente francesa e a corrente inglesa - cuja evolução culminou na análise crítica do discurso - e, por fim, tecemos algumas considerações acerca das possibilidades de uso e de que maneira tal proposta pode auxiliar a romper com algumas práticas de pesquisa tradicionalmente elitistas e excludentes dentro da Ciência da Administração.
\end{abstract}

Palavras-chave: Discurso. Análise do discurso. Ciência da Administração. Empresa.

\section{Abstract}

Considering that both enterprise discourse and scientific discourse (dominant paradigm) constitutes, nowadays, a direct vehicle of manifestation/legitimacy of the current ideology, either to convince, impose, or establish agreements on the individual, in this paper we discuss the characteristics, uses, and possibilities of discourse analysis as a theoretical and methodological proposal that, besides uncovering the belief in a single direction, a single truth, provides resources that allow both promoting theories and practices distant from the hegemonic model and, especially, (re)construct meanings

Artigo submetido em 23 de abril de 2013 e aceito para publicação em 04 de dezembro de 2013.

1 Doutor em administração pela Universidade Federal de Santa Catarina; Professor Adjunto da Universidade Federal de Pelotas; Pesquisador do Observatório da Realidade Organizacional. Endereço: Faculdade de Administração e Turismo da Universidade Federal de Pelotas, Rua Gomes Carneiro, 1 - 4ํaㅁ, andar, CEP 96010-610, Pelotas - RS, Brasil. E-mail: marciosilvarodrigues@gmail.com

${ }^{2}$ Doutora em engenharia de produção pela Universidade Federal de Santa Catarina; Professora associada da Universidade Federal de Santa Catarina; Pesquisadora do Observatório da Realidade Organizacional - Endereço: Universidade Federal de Santa Catarina Centro Sócio Econômico - Curso de Pós Graduação em Administração, Campus Universitário, Trindade, CEP 88040-970, Florianópolis - SC, Brasil. E-mail: eloise@cse.ufsc.br 
and practices, in all aspects of the human life involved, which are, in a certain way, free from pressures and the current discourse and ideology. To implement this proposal, first, we introduce the general notions of discourse and discourse analysis, then, we discuss the characteristics of two discourse analysis schools, the French school and the English school - whose evolution culminated in the critical discourse analysis -, and, finally, we bring forth some considerations about the possibilities of use and the way how this proposal may help breaking with some research practices traditionally elitist and exclusionary within Administration Science.

Keywords: Discourse. Discourse analysis. Administration Science. Enterprise.

Argumentações Iniciais

Mas, o que há, enfim, de tão perigoso no fato de as pessoas falarem e de seus discursos proliferarem indefinidamente? Onde, afinal, está o perigo? (Michel Foucault)

De acordo com Marx (1984, p. 43), "desde sempre pesa sobre o espírito a maldição de estar imbuído de uma matéria que aqui se manifesta sob a forma de camadas de ar em movimento, de sons, numa palavra, sob a forma da linguagem". Para o autor, a linguagem é tão velha quanto a consciência: é a consciência real. "Prática, que existe também para outros homens e que, portanto existe igualmente só para mim e, tal como a consciência" (MARX, 1984, p. 43). Partimos, inicialmente, das palavras de Marx (1984) para ilustrar que, além de não existir significação e conhecimento anteriores ao uso da linguagem (WITTGENSTEIN, 1996), esta, quando compreendida como um processo historicamente situado, revela um conjunto de regras que definem, em certa época e para determinada área social, as condições de exercício da função enunciativa (FOUCAULT, 2004). Dito de outra forma, o discurso cria uma dimensão capaz de estabelecer regras de comportamentos, de condutas e de diálogos comuns a uma classe social, um agrupamento, alguns grupos ou da sociedade inteira, aceitos por todos e legitimados como padrão de conduta a ser adotado pela maioria, com a finalidade de que os atores sociais evitem o conflito entre si (FARIA e MENEGHETTI, 2001). Como enfatizou Foucault (2007), todo discurso representa uma forma de poder e, consequentemente, os discursos que permeiam qualquer campo social são cercados por uma série de disputas, rivalidades e jogos de poder (ver BOURDIEU, 1994). Desse modo, continua Foucault (2007), ao atingir o status de ordem dominante, ou ordem do discurso, determinado discurso, devido ao uso de diversos mecanismos de exclusão, passa a ser controlado, selecionado e redistribuído a partir de certo número de procedimentos ou normas, com o objetivo de conjurar seus poderes e perigos e dominar seus acontecimentos aleatórios. Em decorrência dessa situação, segundo Foucault (2007), é sabido que não se tem o direito de dizer tudo, que não se pode falar de tudo em qualquer circunstância, que qualquer um, enfim, não pode falar ou escrever qualquer coisa, pois o discurso "vencedor", nessa acepção, tornou-se, de certa maneira, uma doxa, no sentido atribuído por Bourdieu (1994).

Em síntese, o termo doxa refere-se a uma atitude natural da vida diária, ou seja, uma coincidência das estruturas sociais e mentais por meio das quais o mundo magicamente aparece como autoevidente e sua composição é posta além do alcance do debate e da elaboração (WACQUANT, 2002). Assim, ao estabelecer o que é "correto", "certo" em oposição ao que é "errado", o discurso dominante, quando entendido como forma de dominação despersonalizada, serve-se dos próprios indivíduos para se perpetuar no poder e diminui, por conseguinte, as formas de contestação. Tal situação garante, de certa forma, a manutenção da doxa, uma vez que, a partir da definição de princípios gerais, o discurso vigente passa a fornecer o ponto de vista a partir do qual a realidade é aprendida e como, diante dele, deveremos nos posicionar. Desse modo, todo aquele que queria ser compreendido ou aceito na sociedade deve adotar o discurso comum a esta para ter credibilidade e situar-se em relação às normas que ela enuncia (delimitação imaginária). Todo discurso que foge disso não será, em parte, entendido, pois se situa fora do campo das representações coletivas que esse quadro de referências delimita. Tal situação, para Bourdieu (1996), recebe o nome de "linguagem autorizada", ou seja, aquilo que pode ser dito porque segue um padrão lógico e coerente com as intenções de cunho político, econômico ou ideológico vigentes. 
Essas considerações servem para ilustrar que a consolidação de determinado discurso, ou modo de "estar" no mundo, constituído por palavras, gestos, expressões e comunicações não verbais, não deve ser compreendida como um processo estanque ou isolado, ao contrário, normalmente ela é tributária de pano de fundo ideológico. Desse modo, determinado discurso, quando ideologicamente comprometido com os valores vigentes, torna-se responsável por consolidar, ou melhor, por legitimar, determinada posição ideológica e, por isso, repassa, por meio da linguagem essa posição, de modo que se faça com que as posições de uns sejam aceitas e tidas como válidas por outros (BOURDIEU, 1996). Em outras palavras, por se caracterizar como um instrumento de dominação que está, na maior parte dos casos, entrelaçado à ideologia vigente, todo discurso carrega dentro de si um conjunto de ideias, pressupostos e práticas que visam incutir, em cada indivíduo que compõe o macrossistema social, os valores sob os quais ele foi erigido.

Transportando essas ideias para um plano mais concreto, percebemos a relação entre discurso e ideologia que pode ser evidenciada, em toda sua magnitude, quando se analisa a emergência da sociedade moderna e a consequente supremacia do mercado diante de outros enclaves sociais. Nesse sentido, argumentamos ser inegável que a consolidação e manutenção dos princípios capitalistas na sociedade moderna deve-se, em grande parte, ao fato de que eles encontraram na empresa e no discurso empresarial sua via material de personificação e disseminação. Corroborando essa afirmação, Cooper e Burrell (2006), em referência a Deleuze e Guatarri, chamam a atenção para a compreensão das organizações, leia-se empresas, como máquinas que produzem discursos elaborados de informação e conhecimento nos quais os sujeitos humanos são uma parte necessária do fluxo material no qual esse discurso está inscrito. Assim, continuam os autores, o discurso não é mais uma extensão das faculdades ou dos órgãos; estes é que são extensões do discurso.

Como consequência direta desse processo e considerando que vivemos em uma sociedade de organizações, servimo-nos das palavras de Guerreiro Ramos (1989), ao se referir à supremacia do mercado materializada a partir do discurso da empresa diante de outros enclaves sociais, para ilustrar que nenhuma sociedade, no passado, jamais esteve na situação de sociedade desenvolvida centrada no mercado de nossos dias, na qual o processo de socialização está, em grande parte, subordinado a uma política cognitiva exercida por vastos complexos empresariais que agem sem nenhum controle. De fato, parece evidente que se a empresa tornouse a instituição central da sociedade moderna, consequentemente, ela se transformou na modeladora da mente dos cidadãos. Em decorrência disso, ao se submeter aos ditames empresariais, o indivíduo produz uma ideologia semelhante à da empresa e necessariamente não contraditória, ou seja, "através de sua submissão a metas organizacionalmente estabelecidas e através da absorção gradual dessas metas em suas próprias atitudes, aquele que participa da organização adquire uma personalidade [discurso] de organização, bastante diferente de sua personalidade como indivíduo" (GUERREIRO RAMOS, 1989, p. 109).

Nesse contexto, enquanto a moderna empresa capitalista tornava-se a instituição de referência de nossa sociedade, no campo científico, segundo Gray (2007), as ciências, ao sobrepujar outras formas de conhecimento, como os mitos, as tradições, as religiões e a filosofia, outorgaram para si o título de detentora da verdade suprema (racional, dogmática e neutra). Embora aparentemente desconexa, tal situação, quando entendida a partir de um processo histórico, também revela um plano ideológico único, ou seja, a proximidade do discurso científico e, mais especificamente, do discurso da Ciência da Administração, com os valores promulgados pela sociedade moderna ou pelo capitalismo.

Desse modo, quando observamos as características gerais que edificaram o paradigma científico dominante, oriundo da associação do positivismo, do funcionalismo e do sistemismo, percebemos claramente que tanto a Administração enquanto ciência como a moderna empresa capitalista foram erigidas com base na associação das características de tal paradigma, ou seja, a partir da racionalização das atividades, com o objetivo de maximizar os resultados, principalmente financeiros, e manter a ordem. Assim, vemos que a Ciência da Administração foi constituída levando em consideração a orientação pecuniária (utilitarismo) e os princípios promulgados pelo paradigma dominante, a saber: a noção de ordem (evolução, continuidade, equilíbrio, sobrevivência), de função (divisão do trabalho, eliminação das variações individuais), de totalidade (supremacia do todo sobre as partes), a negação dos conflitos (concepção integradora e não conflituosa da organização). Como resultado dessa condição, o discurso científico dominante incorpora ou legitima a 
ideologia e as práticas do sistema vigente, e, por conseguinte, também favorece, da mesma forma que o discurso da empresa, as elites e a ordem econômica dominante, tornando-se, assim, como ocorre no capitalismo, excludente e destinada a uma minoria. Como menciona Guerreiro Ramos (1989, p. 1):

[...] a Teoria da Administração, do modo como tem sido concebida é ingênua, porque se baseia na racionalidade instrumental característica da ciência social no Ocidente. Até hoje, essa mesma ingenuidade é a responsável pelo seu sucesso em termos de aplicação prática. Entretanto, esse sucesso é unidimensional e vem exercendo um impacto desfigurador sobre a vida humana associada.

Partindo das referidas explanações, é possível perceber que tanto o discurso da empresa como o discurso científico constitui, atualmente, um veículo de manifestação ou legitimação direta da ideologia vigente, seja para convencer, para impor ou para estabelecer acordos sobre o indivíduo. Mais que isso, tais discursos revelam a supremacia de um mundo sobre todos os outros mundos (SOLÉ, 2000), revelam a doxa promulgada por Bourdieu (1996) e, por conseguinte, tornam cada vez mais difíceis tanto a consolidação de novas posturas científicas como a construção de novos estilos de vida, pois, como disse Bauman (2001) em referência ao pensamento de Cornelius Castoriadis, o que há de errado com a sociedade em que vivemos é que ela deixou de questionar-se. É um tipo de sociedade que não mais reconhece qualquer alternativa para si e, portanto, sente-se absolvida do dever de examinar, demonstrar, justificar a validade de suas suposições tácitas e declaradas. Complementando o pessimismo da referida sentença, consideramos relevante reproduzir, como forma de indicar os possíveis caminhos para superação da nossa atual condição, a visão de Marcuse (1973, p. 277) sobre a sociedade que emergiu sob o manto da ideologia vigente:

[...] em relação a hoje e à nossa própria condição, creio que estamos diante de uma situação nova na história, porque temos que ser libertados de uma sociedade rica, poderosa e que funciona relativamente bem. O problema que enfrentamos é a necessidade de nos libertar de uma sociedade que desenvolve em grande medida as necessidades materiais e culturais do homem - uma sociedade que, para usar um slogan, cumpre o que prometeu a uma parte crescente da população. E isso implica que enfrentamos a libertação de uma sociedade na qual a libertação aparentemente não conta com uma base de massas.

Ora, se segundo Marcuse (1973) a massa tem pouca possibilidade de emancipação do discurso e da ideologia hegemônica, quem seriam os responsáveis por essa transformação? Com surpresa, encontramos uma alternativa em Durkheim (2001), o qual afirma que, enquanto em outros tempos as funções econômicas só tinham um papel secundário, hoje elas ocupam o primeiro plano. Diante delas, vemos as funções militares, administrativas e religiosas recuarem cada vez mais. Segundo o autor, só as funções científicas têm condições de disputar a posição com elas e, mesmo assim, atualmente a ciência só tem prestígio na medida em que pode servir à prática, isto é, em boa parte, às profissões econômicas.

Desse modo, considerando que, para Durkheim (2001), a ciência seria a única responsável pela transformação da ordem vigente e ressaltando, a centralidade do discurso no processo de reprodução social, desenvolvemos este texto com o intuito de discutir, calcado na premissa de que o discurso deve ser entendido como um processo dialógico - no qual o homem é visto como um ser histórico e ideológico -, fruto do diálogo entre discursos e sujeitos (BAKHTIN, 1979), as características, os usos e as possibilidades da análise do discurso como uma proposta teórica e metodológica na qual, além de desnudar a crença em um único sentido, em uma única verdade, em um único discurso, forneça meios a partir do entendimento da linguagem com elemento diretamente relacionada à vida social (FAIRCLOUGH, 2001), que possibilitem promover tanto teorias e práticas distantes do modelo hegemônico como, principalmente, (re)construir sentidos e práticas, em todos os aspectos da vida humana associada, que estejam, de certa maneira, livres das pressões (discurso e ideologia) da empresa. 
Feitas tais considerações, como forma de sistematizar esta discussão, nas seções seguintes apresentamos, primeiramente, noções gerais sobre a análise do discurso. Logo depois, abordamos características das duas principais correntes, a corrente francesa e a corrente inglesa - cuja evolução culminou na análise crítica do discurso. Por fim, após realizar algumas amarrações e com o intuito de ilustrar de que maneira tal proposta pode auxiliar na ruptura com os discursos e com a ideologia vigente, discutimos algumas possibilidades de uso de tal metodologia na Ciência da Administração.

\section{Análise do Discurso: Origens, Contexto e Definições Preliminares}

Partindo do pressuposto de que durante muito tempo a Linguística se assentou, exclusivamente, no estudo das línguas naturais e com o objetivo de demonstrar os primeiros indícios que contribuíram para consolidar a análise do discurso como proposta teórica e metodológica, de pronto, consideramos relevante mencionar as contribuições de Ferdinand de Saussure, para a delimitação metodológica dos estudos linguísticos e sua tentativa de ampliar o uso das teorias propostas por essa área do conhecimento para outros espaços sociais. Segundo o autor: "[em outros tempos] a linguística, jamais se preocupou em determinar a natureza do seu objeto de estudo. Ora, sem essa operação elementar, uma ciência é incapaz de estabelecer um método para si própria" (SAUSSURE, 1987, p. 10). Partindo dessa constatação, Saussure (1987) imaginou a existência de uma disciplina que estudaria os signos no meio da vida social, o que validaria sua penetração em outros campos de estudo da atividade humana. Essa ciência, que ele acreditava fazer parte da psicologia social, recebeu a denominação de Semiologia, uma ciência geral de todos os sistemas de signos, por meio dos quais se estabelece a comunicação entre os homens (CABRAL, 1999).

De modo geral, dentre as inúmeras contribuições do autor em relação aos estudos da linguagem, afora a relação entre significante (imagem acústica) e significado (sentido ou conceito) no processo de construção do signo, a apresentação da dicotomia entre língua e fala representa uma das posições mais marcantes para o tema em questão. De acordo com Saussure (1987), a dicotomia língua e fala relaciona-se à oposição entre o social e o individual, ou seja, a língua enquanto elemento de comunicação entre humanos é uma instituição social e um sistema de valores ao mesmo tempo. Sendo um sistema de valores contratuais, além da existência dos signos como elementos de mediação, a língua resiste às modificações isoladas do indivíduo e, consequentemente, é uma instituição social (BARTHES, 1971). Por outro lado, a fala consiste em um ato individual de seleção e atualização constituído por combinações e mecanismos psicofísicos que possibilitam a exteriorização das combinações. Em síntese, tal dicotomia produziu um objeto teórico do qual ficam excluídos o sujeito, suas marcas espaço-temporais e o sentido, que são relegados ao domínio residual da fala (CABRAL, 1999), pois Saussure (1987) concebia a linguagem como um sistema ou uma estrutura em que qualquer elemento individual não tem sentido fora dos limites dessa estrutura. Mais que isso, ao fazer uma distinção entre fala e língua, o autor aponta uma relativa autonomia da linguagem em relação à realidade. Entretanto, aceitar tal separação consiste em entender a realidade sem quaisquer contextualizações e, nesse sentido, a língua se torna um objeto asséptico, limitando-nos a "buscar o poder das palavras nas palavras, ou seja, a buscá-lo onde ele não se encontra" (BOURDIEU, 1996, p. 85).

Alguns anos mais tarde, reconhecendo as ideias de Saussure (1987) de que a língua é um fato social, cuja existência está calcada nas necessidades de comunicação entre os homens, Mikhail Bakhtin rejeitou o outro extremo da dicotomia, ou seja, a constatação de que a fala representa uma manifestação puramente individual. Sobre esse tema, Bakhtin (1979) argumenta que a matéria linguística, defendida por Saussure (1987), é apenas uma parte do enunciado, uma outra parte, não verbal, que corresponde ao contexto da enunciação, também deve ser incluída na análise linguística. Em decorrência disso, o processo entre a elaboração mental do conteúdo a ser externalizado à sua real objetivação - a fala - tem seu conteúdo orientado socialmente, buscando adaptar-se ao contexto imediato do ato de comunicação e, principalmente, aos interlocutores. Para esse autor, cada ato de enunciação corresponde à realização da intersubjetividade humana. Língua e fala seriam, portanto, conceitos que só podem ser compreendidos enquanto uma relação 
dialética, já que não existe língua sem fala, tampouco existe fala abstraída da língua (BAKHTIN, 1979; ALVES, GOMES e SOUZA, 2006).

A partir dessas considerações, é possível perceber que a fala, seja no sentido saussuriano ou bakhtiniano, deixou de ser vista como mero instrumento de comunicação, ou seja, tanto para Saussure (1987), o qual entende que o sujeito seleciona as combinações a partir da língua para se comunicar, como para Bakhtin (1979), o qual relaciona as partes verbais e não verbais de um enunciado ao contexto no qual ele ocorre, a noção de fala se amplia, tornando-se, de certa maneira, um discurso e passa a ser analisada considerando-se os aspectos ideológicos e/ou históricos que permeiam o interlocutor, com o objetivo de compreender, "além dos próprios enunciados, a intenção do sujeito falante, sua atividade consciente, o que ele quis dizer, ou ainda o jogo inconsciente que emergiu involuntariamente do que disse ou da quase imperceptível fratura de suas palavras manifestas" (FOUCAULT, 2004, p. 31). Além de conhecer a base das ideias dos principais autores que influenciaram a consolidação da análise do discurso e antes de conceituá-la e caracterizá-la efetivamente, entendemos ser relevante desenvolver algumas linhas acerca das noções de discurso e de formação discursiva.

Um rápido olhar sobre os textos que tratam da análise do discurso revela que, afora a evidência do pouco consenso entre os autores, principalmente para aqueles que trabalham com a corrente francesa, o termo discurso é utilizado com grande liberdade e, por conseguinte, de diversas formas. Entretanto, subjacente a cada enunciado, percebe-se a existência de coerência em cada um dos conceitos, ou seja, termos como ideologia, contexto social, história, tempo, poder, linguagem, entre outros; estão presentes tanto explícita como implicitamente em cada uma das definições de discurso. Além disso, identificamos que alguns autores optam, com vistas a eliminar a dificuldade de delimitar o objeto de estudo da análise do discurso, pelo uso do conceito de formação discursiva de Foucault (2004). De fato, esse conceito se mostra útil, uma vez que serve como delimitador do objeto para ambas as correntes que serão tratadas a seguir, a corrente francesa e a corrente inglesa.

As formações discursivas condicionam, controlam e delimitam a forma de ver os fatos, de conceituar as coisas e as práticas sociais. Mais que isso, Daudi (1986), afirma que, aos termos teoria, disciplina e ciência, tidos como historicamente carregados, Foucault (2004) prefere a expressão formação discursiva, que sugere que uma teoria ou ciência nunca está plenamente desenvolvida. Ao formar uma unidade, um conjunto de enunciados pode ser moldado em uma teoria científica, que constitui um discurso sobre alguma coisa. Assim, a formação discursiva torna-se um processo de desenvolvimento e construção que, a partir de enunciados dispersos, formam um discurso. Dessas considerações, entendemos que a formação discursiva, além de determinar, de certa maneira, o que pode e deve ser dito, revela a proximidade entre discurso e poder, pois, partindo da noção de Althusser (1999) de que o indivíduo é livremente assujeitado para livremente se submeter às ordens de um sujeito absoluto e universal, ou determinado discurso, tal assujeitamento faz com que cada um seja conduzido sem se dar conta e tendo a impressão de estar exercendo sua livre vontade, a ocupar seu lugar na sociedade (PÊCHEUX e FUCHS, 1990).

Relacionando tais discussões à centralidade da empresa e considerando, como mencionado, o papel de seu discurso na construção de identidades individuais e sociais, é importante reproduzir as palavras de Faria e Meneghetti (2001) acerca do controle do discurso e, consequentemente, da manutenção da ideologia. Para os autores,

[...] todo discurso esconde uma rede simbólica de relações de dominação ideológica e de poder. Cada palavra expressa no ambiente organizacional está, de alguma forma, sendo monitorada e classificada. Todo discurso que destoa da sinfonia organizacional é reprimido, não necessariamente através de punições coercitivas explicitas aplicada pela direção central da organização, mas através dos grupos internos, do controle psíquico da ideologia. Há uma delimitação imaginária [...], em que o indivíduo pode se aventurar com o uso de suas palavras, diálogos e argumentações, devendo estar, contudo, atento para que o seu discurso 
não ponha em risco os grupos dominantes e a ideologia vigente na organização (FARIA e MENEGHETTI, 2001, p. 1).

Ao buscar compreender como a linguagem produz sentido e relacionando-a com sua exterioridade, a análise do discurso, segundo Maingueneau (1993), pode significar quase qualquer coisa, uma vez que toda a produção de linguagem pode ser considerada um discurso. Apesar disso, em termos gerais, a análise do discurso, segundo Orlandi (2002), não trata, especificamente, da língua ou da gramática, embora todas essas coisas lhe interessem, o objeto de estudo que interessa é o discurso e sua forma de produção de sentido. Assim, ao perseguir o desafio de construir interpretações, a análise do discurso parte do pressuposto de que um sentido oculto deve ser captado, o qual, sem uma técnica apropriada, permanece inacessível. A busca da significação oculta não implica a crença em um único sentido, o foco de interesse é a construção de procedimentos capazes de transportar o leitor a compreensões menos óbvias, mais profundas, por meio da desconstrução do literal, do imediato (MAINGUENEAU, 2005).

Desse modo, como afirmou Cabral (1999), a análise do discurso almeja demonstrar que aquilo que é lido não é a realidade, mas apenas um relato da realidade propositadamente construído de determinado modo por determinado sujeito. Ao destrinchar o funcionamento dos textos e da consequente observação de sua articulação com as formações ideológicas, ela possibilita desvendar, no contexto da sociedade, o confronto de forças, as relações de poder, os domínios do saber (CABRAL, 1999). Outrossim, a análise do discurso considera essencial a relação da linguagem com a exterioridade, que pode ser compreendida como as condições de produção do discurso. Nessas condições estão incluídos não apenas o falante e o ouvinte, mas, também, o contexto histórico-social e ideológico da comunicação. Embora adote conceitos estritamente técnicos advindos da Linguística, a análise do discurso, enquanto técnica ou perspectiva de pesquisa, não é uma abordagem hermética, de domínio exclusivo dos linguistas. Ela engloba e pressupõe uma variedade de conhecimentos de áreas afins, como a Psicologia, a Sociologia e a Filosofia (CABRAL, 1999). Assim, desvendando os mistérios da linguagem, rompendo a opacidade das palavras e das frases, desvelando os segredos dos subentendidos, penetrando nos implícitos do dito, essa análise vem compondo um instrumental metodológico que, a partir do conceito de discurso, possibilita compreender seus sentidos múltiplos criados por meio da complexa trama de atores que o realizam (BALLALAI, 1989).

Enquanto estratégia de pesquisa, a análise do discurso é de difícil caracterização. Segundo Cabral (1999), sua aparente volatilidade advém do fato de que seu objeto ora se perspectiva linguisticamente, ora ideologicamente, caracterizando, talvez, uma pretensa antinomia que, se por um lado favorece um maior aprofundamento em cada uma dessas abordagens, por outro, impede a visão da totalidade, postura frequentemente distante dos princípios funcionalistas. Ademais, segundo Orlandi (2002), enquanto as abordagens qualitativas tradicionais comumente assumem um mundo social e, a partir daí, procuram entender o significado desse mundo para os participantes, a análise do discurso, por outro lado, tenta explorar como as ideias e os objetos socialmente produzidos que existem no mundo foram criados e como eles se mantêm ao longo do tempo. Sob essa perspectiva, é possível inferir uma das características mais marcantes da análise do discurso, ou seja, se por um lado as perspectivas tradicionais de pesquisa tanto quantitativas como qualitativas contentam-se em descrever e interpretar determinada realidade social, tal perspectiva, além de revelar as relações de poder subjacentes ao processo de construção da realidade, ao desnudar as concepções convencionalmente instauradas pela ideologia vigente, ocupa-se diretamente da crítica e da denúncia e, em alguns casos, das formas de emancipação.

Afora as características gerais que permeiam a análise do discurso e devido à sua interdisciplinaridade, a multiplicidade de significados e usos que se pode fazer dessa abordagem, percebemos que esta pode ser dividida em duas grandes linhas: a corrente francesa e a corrente inglesa. A linha francesa, oriunda dos trabalhos de Saussure, Pêcheux e dos princípios promulgados pelos estruturalistas, busca, ao atrelar uma perspectiva histórica à análise do texto, explicitar as relações entre linguagem e ideologia, destacando o assujeitamento que reproduz formações discursivas historicamente constituídas. Para desenvolver essa proposta, a corrente francesa extrapola os limites da linguística e busca desvendar as questões filosóficas, políticas, culturais, econômicas que permeiam o texto. A linha anglo-saxônica, por outro lado, ainda que 
inspirada nos trabalhos iniciais da corrente anterior, ao se apoiar nos enfoques interacionistas e etnometodológicos (oriundos da Antropologia), ocupa-se da oralidade (comunicação cotidiana) e dos sistemas sociológicos que a permeiam. Assim, a corrente inglesa propõe um enfoque intraliguístico a partir das interações entre os níveis sintático e semântico, bem como das questões entre coesão e coerência da linguagem. Diferentemente da anterior, essa linha não se ocupa da análise do sujeito enquanto reprodutor de formações discursivas, clivado por ideologias, mas, sim, da investigação das consequências sociais e políticas que se originam dessa reprodução discursiva. Em síntese, é possível dizer que enquanto a linha francesa se importa com o modo como a materialidade enunciativa evidencia um sujeito reprodutor de formações discursivas, a linha inglesa se preocupa com categorizações inerentes a essa materialidade enunciativa com vistas a desvelar (e/ou desafiar) a enunciação propriamente dita.

Das tradições supracitadas, duas grandes propostas emergiram com o intuito de realizar a análise do discurso: uma derivada da corrente francesa, comumente denominada análise do discurso (AD) e outra, de origem inglesa, que, depois de diversos desdobramentos, culminou no surgimento da análise crítica do discurso (ACD).

\section{Um Objeto, Duas Perspectivas}

Nesta seção, discorremos inicialmente acerca da AD defendida pela corrente francesa, a partir das ideias de seu principal expoente: Michel Pêcheux. Logo depois, com o objetivo de realizar uma análise comparativa, descrevemos, com base nos trabalhos de Norman Fairclough, as principais características da ACD, uma teoria e um método oriundos da tradição inglesa.

\section{Análise do discurso: a perspectiva de Michel Pêcheux}

Partindo da noção de que o discurso representa um lugar particular no qual a linguagem materializa a ideologia, Michel Pêcheux busca teorizar acerca dos mecanismos de determinação histórica que possibilitam explicitar o funcionamento discursivo. Desse modo, o autor em questão auxilia na construção da $\mathrm{AD}$, enquanto disciplina e método, que, de modo geral, vai articular o linguístico, o sócio-histórico e o ideológico, colocando a linguagem na relação com os modos de produção social. Segundo Orlandi (2002), como não há discurso sem sujeito e não há sujeito sem ideologia, existe entre os diferentes modos de produção social um modo de produção social especifico - simbólico e materializado por meio do discurso. Assim, com a caracterização dos funcionamentos discursivos e da consideração de que o sujeito é uma parte do processo de produção do sentido, o qual é ideologicamente comprometido, a AD procura, a partir do estabelecimento da propriedade do discurso e de suas condições de produção, estabelecer a relação entre o linguístico e o ideológico - detectando marcas e propriedades do discurso (ORLANDI, 2002). Quando entendida a partir de um processo histórico, a AD de Pêcheux pode ser dividida em três fases distintas. A primeira fase foi inaugurada com o lançamento do livro Por uma análise automática do discurso (GADET e HAK, 1990). Nela, além de definir que o discurso é efeito de sentido entre interlocutores, Pêcheux e Fuchs (1990) esforçam-se para realizar uma análise automática, objetiva, geral e universal dos discursos (ORLANDI, 2002). Desenvolvida a partir do estruturalismo harrisiano, tal análise buscava colocar em evidência traços dos processos discursivos, a fim de determinar os enunciados de base produzidos pela "maquina discursiva" (GREGOLIN, 2004). Em um segundo momento, ao se aproximar das discussões filosóficas e das noções de formação discursiva de Foucault, de arqueologia e de interdiscursividade, Pêcheux rejeita, de certa forma, suas ideias anteriores e propõe, ao afirmar que o sujeito é afetado pelo inconsciente e interpelado pela ideologia, um aprimoramento teórico para a AD. Refinando as relações entre língua, discurso, ideologia e sujeito, é nessa fase que Pêcheux formula a teoria dos dois esquecimentos, a qual enfatiza que "sob a ação da interpelação ideológica, o sujeito pensa que é a fonte do dizer pois esse se apresenta como uma evidência" (GREGOLIN, 2004, p. 62). 
Por fim, segundo Orlandi (2002), ao propor uma inovação metodológica (gesto de leitura) e uma sofisticação no tratamento do sujeito (a questão da dispersão do sujeito e suas posições na formação discursiva entram em cena para acabar a ideia do sujeito comportado em seu assujeitamento a uma forma-sujeito histórica determinada), Pêcheux inaugura a terceira e última fase de desenvolvimento da $\mathrm{AD}$ da corrente francesa. Explorando as condições de produção de um discurso, nessa fase, duas noções tornam-se centrais: a noção de interdiscurso e a de intradiscurso. Segundo Pêcheux (1995), o interdiscurso diz respeito a todo complexo dominante de formações discursivas. Imbricado no complexo das formações ideológicas, o interdiscurso é a memória do dizer, o exterior constitutivo do discurso, isto é, o lugar de onde se constituem os objetos do saber. Para Orlandi (2002), esse exterior constitutivo, responsável pelos sentidos que provêm de outro lugar, mostra a necessidade dos movimentos parafrásticos e polissêmicos para a constituição dos sentidos. Assim, apesar de não ser possível inaugurar um sentido completamente novo, pois ele não seria compreendido, o novo surge a partir de deslocamentos do já dito, isto é, da memória do dizer (ORLANDI, 2002). Daí emerge a ideia de intradiscurso. Considerada por Pêcheux (1995) um efeito do interdiscurso sobre si, o intradiscurso revela a relação do sujeito com suas formulações, isto é, com aquilo que, diante das condições dadas, ele diz naquele momento. Em síntese, tomando o discurso como um processo que se dá sobre a língua, do cruzamento entre uma memória (interdiscurso) e de uma atualização do já dito (intradiscurso) (ORLANDI, 2002), emerge a ideia de enunciação e, por implicação, de discurso que a AD mantém até hoje.

As noções desenvolvidas nessa terceira fase assentam-se, basicamente, em três vertentes: a subjetividade (psicanálise) - o materialismo histórico; a linguística; e a teoria do discurso. Da vertente do materialismo histórico a AD extraiu a noção de superestrutura e do modo de produção que domina a sociedade. Partindo da ideia de Althusser (1999) de que a ideologia é uma representação da relação imaginária dos indivíduos com suas condições reais de existência, a AD procura demonstrar com um determinado discurso reflete a ideologia enquanto produtora de sentido. Da a Linguística, a AD incorporou as discussões acerca da teoria dos mecanismos sintáticos e dos processos de enunciação. Partindo da ideia de que a língua é o lugar material onde se constroem os sentidos, Pêcheux e Fuchs (1990) enfatizam que se torna impossível analisar um discurso como um texto, isto é, como uma sequência linguística fechada em si, mas é preciso referi-lo ao conjunto de discursos possíveis, a partir das circunstâncias em que ele foi produzido. Desse modo, a AD, com sua origem ligada ao político, acaba por inaugurar uma nova percepção do político, pela sobrevivência com a materialidade da linguagem, materialidade esta ao mesmo tempo linguística e histórica (ORLANDI, 2002). Por fim, a vertente da teoria do discurso é utilizada para determinar historicamente os processos semânticos, uma vez que, diretamente associada aos processos linguísticos e históricos, o processo semântico está vinculado à exterioridade ou à ideologia do discurso.

\section{A análise crítica do discurso de Norman Fairclough}

Segundo Fairclough (2001), todo discurso é um conjunto inter-relacionado de textos e de práticas de produção, distribuição e consumo. Além disso, para o autor, ele não é apenas um modo de ação, uma forma das pessoas agirem sobre o mundo e sobre os outros, mas, também, é um modo de representação e construção da realidade, o discurso é tanto uma prática de representação do mundo como de significação dele, uma relação dialética entre discurso e estrutura social. Com base nessas ideias, Fairclough (2001) propõe um modelo teórico-metodológico que se interessa particularmente pela linguagem como prática social, tendo seu foco tanto nos processos e nas práticas sociais como no papel do discurso na produção e/ou reprodução de relações assimétricas de poder. Em outras palavras, o autor desenvolve aquilo que é chamado de ACD. Oriunda da teoria social do discurso, assentada na percepção da linguagem como parte irredutível da vida social e privilegiando uma postura emancipatória, a ACD procura compreender quais estruturas, estratégias e outras propriedades de textos, da fala, da interação verbal ou de eventos comunicativos exercem um papel nos modos de produção e reprodução de estrutura da dominação (VAN DIJK, 1993). Portanto, a ACD não é apenas um método para realização de investigações qualitativas e estruturadas de texto; ela explora como as ideias e objetos produzidos socialmente constroem determinada realidade social (FAIRCLOUGH, 2003; BREI e MISOCZKY, 2007). 
Com vistas a operacionalizar essa proposta, Fairclough (2001), além de apoiar-se na linguística sistêmicofuncional e na linguística crítica, ambas oriundas dos trabalhos e Halliday, afirma que o discurso deve ser considerado uma prática de significação do mundo, uma vez que contribui para: 1) a construção do que é referido como "identidades sociais" e posições de sujeito, para o sujeito social e os tipos de eu; 2) para a construção das relações sociais; e 3) para a construção de sistemas de conhecimento e crença. Esses três efeitos do discurso correspondem a três dimensões de sentido ou de funções da linguagem que esse autor, inspirado nas metafunções de Halliday (1994), distingue em: 1) identitária - como as identidades sociais são estabelecidas no discurso; 2) relacional - como as relações sociais são representadas e negociadas; e 3) ideacional - como os textos significam o mundo e seus processos, identidades e relações.

Partindo dessas considerações sobre o discurso, Fairclough (2001), em uma tentativa de reunir três tradições analíticas (a tradição da análise textual e linguística, a tradição microsociológica que considera a prática social como produzida e entendida pelas pessoas com base em procedimentos compartilhados do senso comum e a tradição macrossociológica de análise da prática social em relação as estruturas sociais), propõe um conceito tridimensional para o discurso e para a ACD, uma vez que em qualquer evento discursivo ocorrem simultaneamente:

1) um texto, sobre o qual é feita uma análise linguística; 2) uma prática discursiva, ou interação, que trata dos processos de produção, distribuição e interpretação ou consumo textual [...]; e 3) uma prática social, que foca sua atenção nas situações institucionais e organizacionais do evento discursivo e na maneira pela qual elas dão forma à natureza da prática discursiva e produzem efeitos constitutivos e construtivos das entidades e relações sociais (ROSA FILHO e MISOCZKY, 2006, p. 6-7).

De uma maneira geral, de acordo com Fairclough (2001), a ligação entre texto e prática social é mediada pela prática discursiva, que envolve a produção, a distribuição e o consumo dos textos; gerados a partir de processos sociais e interpretados por indivíduos ou grupos que produzem, de acordo com seu posicionamento dentro das estruturas e dos processos sociais, significados oriundos de suas interações com esses mesmos textos. Desse modo, ao explorar como os textos adquirem significados por meio da relação entre texto, discurso e contexto e como eles contribuem para a constituição da realidade social, por meio dessa construção de significado, o modelo tridimensional de AD, segundo Fairclough (2001), visa a 1) explorar de modo sistemático as relações frequentemente opacas de causalidade e determinação entre a) práticas discursivas (eventos e textos) e b) estruturas sociais (relações e processos mais amplos); 2) investigar como essas práticas, eventos e textos surgem de relações e lutas de poder; e 3) explorar como a opacidade das relações entre o discurso e a sociedade é constitui um fator que assegura o poder e a hegemonia (FAIRCLOUGH, 2001). Assim, a proposta de Fairclough (2001) orienta-se para o estabelecimento de conexões explanatórias entre os modos de organização e interpretação textual, identificando como os textos são produzidos, distribuídos e consumidos em um sentido mais amplo e a natureza da prática social em termos de sua relação com as estruturas e lutas sociais. Nesse sentido, para Fairclough (2001), o discurso é entendido como uma prática política e ideológica, ou seja: 1) uma prática política, uma vez que estabelece, mantém e transforma as relações de poder e as entidades coletivas; e 2) uma prática ideológica, pois constitui, naturaliza, mantém e transforma os significados do mundo de posições diversas nas relações de poder (FAIRCLOUGH, 2001). Assim, tal proposta é crítica, uma vez que busca desnudar, analisar as conexões entre discurso, ideologia e política, conexões majoritariamente obscuras, dificilmente percebidas pelos sujeitos envolvidos, logo, facilmente naturalizadas, reproduzidas e não contestadas (FAIRCLOUGH, 2001). Contudo, se a prática discursiva, consolidada pela produção, distribuição e consumo de textos é uma faceta da luta hegemônica que contribui em diferentes graus para a reprodução ou para a transformação das relações de poder, para além da ordem do discurso, a ACD proposta por Fairclough, ao se centrar, principalmente, nesse ponto, procura identificar, analisar e denunciar as maneiras pelas quais o abuso do poder social, a dominação e a desigualdade são produzidos, reproduzidos e resistidos por meio de textos presentes no contexto social. 


\section{Por Outras Possibilidades: Amarrações e Reflexões Finais}

Após essa breve discussão sobre as diferentes posições da $\mathrm{AD}$, almejamos inicialmente, apresentar algumas considerações acerca das principais divergências e convergências entre as duas abordagens discutidas na seção anterior: a AD da corrente francesa - apresentada a partir das ideias de Michel Pêcheux - e a ACD da corrente inglesa - discutida com base nas ideias de seu principal expoente, Norman Fairclough. Por fim, transportando tais discussões para dentro da Ciência da Administração e retomando a discussão da supremacia de um mundo sobre todos os outros, produzido, reproduzido e disseminado a partir de determinado discurso, buscamos, a partir de três sugestões de pesquisa, demonstrar como a AD em ambas abordagens pode representar uma alternativa, considerando a centralidade (poder) da ciência, no processo de criação de discursos distantes da ideologia vigente, de superação, ou, no mínimo, de denúncia, das formas tradicionalmente arraigadas e legitimadas de controle e dominação social.

De modo geral, embora as duas abordagens relacionem discurso com ideologia, um dos principais aspectos que as distancia reside justamente nesse ponto. Avesso à doutrina da reificação e da correspondente alienação, Althusser (1980) produz sua teoria da ideologia a partir da psicanálise lacaniana e de algumas características do trabalho de Gramsci (EAGLETON, 1997). Nela, ele descreve sua visão sobre o modo por meio do qual a ideologia opera no processo de constituir sujeitos a partir de indivíduos concretos (ALTHUSSER, 1980). Essa constituição dos sujeitos ocorre por meio de um reconhecimento ideológico, de um processo de identificação com a ideologia, ou de um reconhecimento de si em alguma ideologia - a proposição é que a ideologia opera por meio da interpelação do sujeito (MISOCZKY, 2004). Segundo Fairclough (2001), a obra de Althusser, ao exagerar na constituição ideológica dos sujeitos, tende a limitar ou subestimar a capacidade desses sujeitos agirem, individual ou coletivamente, em direção à modificação da ideologia vigente. Por conseguinte, se a AD adota a concepção althusseriana de ideologia, poderíamos supor, à primeira vista, que ela parte do reconhecimento de que o sujeito teria pouco ou nenhum poder para propor modificações no discurso dominante. No entanto, basta resgatar as noções de interdiscurso e intradiscurso para perceber que a $\mathrm{AD}$ não radicaliza o uso da ideologia da maneira descrita por Fairclough. Isto é, ela enxerga no processo de enunciação, fruto do cruzamento entre aquelas duas noções, a possibilidade de ocorrer deslizes e/ou deslocamentos discursivos. Oriundo do embate entre estrutura e acontecimento, entre interdiscurso e intradiscurso, tais deslizes constituem elementos, em espaços centrais à criação do novo e demonstram o papel do sujeito no processo de (re)siginificação (ORLANDI, 2002).

Ao tomar como máxima a postura emancipatória, a $\mathrm{ACD}$, por sua vez, rejeita os pressupostos althusserianos de ideologia e incorpora as noções de hegemonia de Gramsci e de ideologia de Thompson (2009). Partindo da ideia de que a hegemonia está relacionada com uma posição temporária e parcial de interpretação da realidade, Pereira e Misoczky (2007) salientam que a teoria de ideologia proposta por Thompson (2009) é utilizada como complemento e aliada para o estudo dos modos de operação da ideologia nos textos analisados. Thompson (2009, p. 79) conceitua ideologia

[...] em termos das maneiras como o sentido, mobilizado pelas formas simbólicas, serve para estabelecer e sustentar relações de dominação: estabelecer, querendo significar que o sentido pode criar ativamente e instituir relações de dominação; sustentar, querendo significar que o sentido pode servir para manter e reproduzir relações de dominação através de um contínuo processo de produção e recepção de formas simbólicas.

$\mathrm{Na}$ análise da ideologia interessam as maneiras como formas simbólicas se entrecruzam com relações de poder e, portanto, com lutas hegemônicas (PEREIRA e MISOCZKY, 2007). Assim, mais que identificar os modos de operação da ideologia (legitimação, dissimulação, unificação, fragmentação e reificação), é crucial indicar como eles podem estar ligados, em circunstâncias particulares, com estratégias de construção simbólica (THOMPSON, 2009). Pois, afinal, desvendar os efeitos da ideologia sobre o texto e, principalmente, do texto na sustentação ou na transformação da ideologia constitui um dos objetivos centrais da ACD (FAIRGLOUGH, 2003). 
Em relação aos pontos em comum entre a $\mathrm{AD}$ e a $\mathrm{ACD}$, embora já tenham sido mencionadas em outros momentos, merecem destaque: 1) apesar de incorporarem perspectivas diversas no desenvolvimento de suas propostas, ambas abordagens partem da concepção de discurso e de formação discursiva propostas por Foucault $(2004 ; 2007) ; 2)$ tanto a AD como a ACD se servem de alguns princípios marxistas, dentre eles a dialética; 3) as duas, por se apoiarem em aspectos qualitativos e subjetivos, distanciam-se, em termos epistemológicos e metodológicos, dos princípios promulgados pelo paradigma científico vigente (BURRELL e MORGAN, 1979); e 4) tanto por incorporar diversas áreas do conhecimento na construção de suas propostas como por ampliar seus usos para outros campos científicos, podemos auferir que a AD e a ACD primam pela adoção de posturas inter e transdisciplinares.

Afora tal questionamento e considerando nossas discussões realizadas, ao se ocupar da crítica e da desfamirialização (SANTOS, 2000) com o que está estabelecido e é convencionalmente aceito como normal, virtual, inevitável e necessário, tais posturas, além de proporcionar a autorreflexividade, podem, em termos de prática de pesquisa científica, contribuir para o desenvolvimento de estratégias distantes paradigma vigente, e, em alguns casos (ACD), estabelecer um novo senso comum emancipatório. Pois, como afirmou Ballalai (1989), por meio de um processo de desconstrução sistemática, a AD (corrente francesa ou inglesa) constrói um novo entender dos discursos produzidos em uma área, quase sempre voltada à definição política e ideológica que estes encobrem. Ao mesmo tempo que ela constitui, dado o tipo de tom, de abordagem e de discussão esperados, uma de suas principais limitações, essa orientação à denúncia é uma das maiores forças da $\mathrm{AD}$ enquanto metodologia na Ciência da Administração, haja vista seu constante esforço para desmascarar a palavra, a verdade que ela obscurece, o não dito sobre ela e as práticas que ela sustenta.

Em referência a David Hume, Dumont (2000, p. 32) salienta que "os pontos de vista mais familiares são suscetíveis, por esta mesma razão, de nos escaparem". Para o autor em questão, em toda sociedade, os elementos e as ideias fundamentais que a sustentam são tão evidentes e onipresentes que não têm necessidade de ser expressos e, muito menos, questionados. Esse processo (não questionar os pontos de vista evidentes) é, aparentemente, cada vez mais comum e, por isso, partimos de certos referenciais, expressando somente seus predicados e não tomamos consciência do sujeito, da natureza das coisas. Tal desconsideração acarreta, em maior ou menor medida, a naturalização de fenômenos históricos. Transpondo tais ideias para a Ciência da Administração, a AD e a ACD podem servir, por exemplo, para caracterizar e desnaturalizar um de seus objetos centrais. De acordo com Solè (2008), por partir da falsa evidência de que se trata da instituição característica, fundamental e onipresente em nosso mundo, a questão - o que é uma empresa? raramente é levantada pelos sujeitos. Tal questionamento, ao aclarar a singularidade dessa instituição, revelaria seu lugar na história, os discursos que a sustentam e, principalmente, as implicações de sua centralidade - além daquelas discutidas por Solè (2008), Abraham (2006), Du Gay (2004), Salaman e Storey (2008), Ainsworth e Hardy (2008), Fournier e Grey (1999) e Harvey (1989).

Como afirmou Foucault (2008), o discurso não se encontra em um único ponto no qual surgem diversas ramificações, ao contrário, ele existe e ocorre de forma contínua, circular e constante, em todas as relações, uma vez que não existem posições fora desse poder (seja como força geradora ou de oposição). Emanados por um conjunto decididamente heterogêneo de instituições que, inscritas em um jogo de poder e sempre ligadas a uma ou às demais configurações de saber que deles nascem (nesse caso, a modernidade), mas que igualmente os condicionam, os discursos, continua o autor, cumprem uma função estratégica dominante: manter determinada verdade (FOUCAULT, 2008). Desse modo, é possível entender a construção e a consolidação da empresa como um processo no qual outras importantes instituições também constroem e disseminam discursos que a sustentam e são sustentados por aquela primeira. Se for assim, para além da AD da empresa em si, a AD e, em especial, a ACD também pode, tal como demonstrou Rodrigues (2013) através da mídia, auxiliar a revelar como, mesmo tratando de temas distantes da esfera econômica, os discursos produzidos e disseminados por determinadas instituições contribuem para construir e manter a empresa.

Longe de ser as únicas, seja por sua relação com as outras duas e/ou por sua contribuição à área, uma última possibilidade de uso da $\mathrm{AD}$ merece destaque aqui. Lembrando que grande parte dos conhecimentos, teorias, métodos e práticas gerados pela Ciência da Administração são oriundos de outros contextos, normalmente do 
contexto americano, ao adotar a $\mathrm{AD}$ ou $\mathrm{ACD}$, dispomos de mais um importante elemento para realizar aquilo que Guerreiro Ramos (1996) denominou redução sociológica. A adoção dessa postura crítica no campo da produção científica da administração (em geral) e da análise da empresa (em particular) estabelece a possibilidade de evitar o que Dussel (2006) caracteriza como atitude sucursaleira, ou seja, tratar dos conhecimentos oriundos de outros contextos como se fosse uma sucursal na qual as teorias são aplicadas sem qualquer consideração/adaptação à realidade abordada.

Por fim, se, como disse Guerreiro Ramos (1989), precisamos urgentemente de um modelo alternativo de pensamento ainda não articulado em termos sistemáticos, não podemos desprezar as estratégias que nos auxiliam em tal tarefa. Não negando nossa inclinação para a ACD, a intenção deste artigo foi justamente essa: discutir alternativas teóricas e metodológicas para a construção e/ou para a revelação de estratégias emancipatórias tanto de pesquisa como de outras práticas. Ele foi escrito por quem e para quem acredita em outra possibilidade e no papel do pensamento crítico nesse processo.

\section{Referências}

ABRAHAM, Y. M. L'entreprise est-elle nécessaire? In: DUPUIS, J. P. (Org.). Sociologie de l'entreprise. Montréal: Gaëtan Morin, 2006. p. 323-374.

AINSWORTH, S.; HARDY C. The enterprising self: an unsuitable job for an older worker. Organization, v. 15, n. 3, p. 389-405, 2008.

ALTHUSSER, L. Ideologia e aparelhos ideológicos do Estado. 3. ed Lisboa: Presença, 1980.

Sobre a reprodução. Petrópolis, RJ: Vozes, 1999.

ALVES, M. A.; GOMES, M. V. P.; SOUZA, C. M. L. Análise do discurso no Brasil: será ela crítica? In: EnANPAD, 30., 2006, Salvador. Anais... Salvador: ANPAD, 2006. p. 1-16

BAKHTIN, M. Marxismo e filosofia da linguagem. São Paulo: Hucitec, 1979.

BALLALAI, R. Notas e subsídios para a análise do discurso: uma contribuição à leitura do discurso da administração. Fórum Educacional, v. 13, n. 1/2, p. 56-80, 1989.

BARTHES, R. Ensaios críticos. Lisboa: Ed. 70, 1971.

BAUMAN, Z. Modernidade líquida. Rio de Janeiro: Zahar, 2001.

BOURDIEU, P. Sociologia. São Paulo: Ática, 1994.

. A economia das trocas linguísticas. São Paulo: Edusp, 1996.

BREI, V.; MISOCZKY, M. C. O poder simbólico do discurso da água e a reorganização do campo da água potável na França. In: EnANPAD, 31., 2006, Rio de Janeiro. Anais... Rio de Janeiro: ANPAD, 2007. p. 1-16.

BURREL, G.; MORGAN, G. Sociological paradigms and organizational analysis. London: Heinemann, 1979.

CABRAL, A. C. A análise do discurso como estratégia de pesquisa no campo da administração: um olhar inicial. In: EnANPAD, 23., 1999, Foz do Iguaçu. Anais... Foz do Iguaçu, PR: ANPAD, 1999. p. 1-16. 
COOPER, R.; BURRELL, G. Modernismo, pós-modernismo e análise organizacional: uma introdução. Revista de Administração de Empresas, v. 46, n. 1, p. 87-101, 2006.

DAUDI, P. Power in the organization: the discourse of power in managerial praxis. Oxford: Basil Blackwell, 1986.

DU GAY, P. Against 'enterprise' (but not against 'enterprise', for that would make no sense). Organization, v. 11, $\mathrm{n}$. 1, p. 37-57, 2004.

DUMONT, L. Homo aequalis: gênese e plenitude da ideologia econômica. Bauru, SP: Edusc, 2000.

DURKHEIM, É. As regras do método sociológico. São Paulo: Martin Claret, 2001.

DUSSEL, E. Vivemos uma primavera política. Florianópolis: UFSC, 2006. Não publicado.

EAGLETON, T. Ideologia: uma introdução. São Paulo: Ed. Unesp/Boitempo, 1997.

FAIRCLOUGH, N. Discurso e mudança social. Brasília, DF: Ed. UnB, 2001.

Analysing discourse: textual analysis for social research. London: Routledge, 2003.

FARIA, J. H. F.; MENEGHETTI, F. K. Discursos organizacionais. In: EnANPAD, 25., 2001, Campinas. Anais... Campinas, SP: ANPAD, 2001. p. 1-16.

FOUCAULT, M. A arqueologia do saber. 7. ed. Rio de Janeiro: Forense Universitária, 2004.

. A ordem do discurso. 15. ed. São Paulo: Loyola, 2007.

. Microfísica do poder. Rio de Janeiro: Graal, 2008.

FOURNIER, V.; GREY, C. Too much, too little and too often: a critique of du Gay's analysis of enterprise. Organization, v. 6, n. 1, p. 107-128, 1999.

GADET, F.; HAK, T. (Org.). Por uma análise automática do discurso. Campinas, SP: Ed. Unicamp, 1990.

GRAY, J. Cachorros de palha: reflexões sobre humanos e outros animais. Rio de Janeiro: Record, 2007.

GREGOLIN, M. R. V. Foucault e Pêcheux na análise do discurso: diálogos e duelos. São Carlos: Claraluz, 2004.

GUERREIRO RAMOS, A. A nova ciência das organizações. Rio de Janeiro: Ed. FGV, 1989.

A Redução Sociológica. Rio de Janeiro: Editora da UFRJ, 1996.

HALLIDAY, M. A. K. An introduction to functional grammar. London: Arnold, 1994.

HARVEY, D. From managerialism to entrepreneurialism: the transformation in urban governance in late capitalism. Geografiska Annaler, v. 71, n. 1, p. 3-17, 1989.

MAINGUENEAU, D. Novas tendências em análise do discurso. Campinas, SP: Unicamp, 1993.

Gênese dos discursos. Trad. Sírio Possenti. Curitiba: Criar, 2005.

MARCUSE, H. A ideologia da sociedade industrial. Rio de Janeiro: Jorge Zahar, 1973. 
MARX, K. A ideologia alemã. São Paulo: Hucitec, 1984.

MISOCZKY, M. C. Estudos críticos do discurso. Porto Alegre: Ed. UFGRS, 2004. Não publicado.

ORLANDI, E. Análise de discurso: princípios e procedimentos. Campinas, SP: Pontes, 2002.

PÊCHEUX, M. Semântica e discurso. Campinas, SP: Ed. Unicamp, 1995.

; FUCHS, C. A propósito da análise automática do discurso. In: GADET, F.; HAK, T. (Org.). Por uma análise automática do discurso: uma introdução a obra de Michel Pecheux. Campinas, SP: Ed. Unicamp, 1990. p. $163-252$.

PEREIRA, I. M.; MISOCZKY, M. C. Peter Drucker e a legitimação do capitalismo tardio: uma análise crítica de discurso In: EnANPAD, 30., 2006, Salvador. Anais... Salvador: ANPAD, 2006. p. 1-16.

RODRIGUES, M. S. O novo ministério da verdade: o discurso de Veja sobre o campo do ensino superior e a consolidação da empresa no Brasil. 410 f. Tese (Doutorado em Administração) - Universidade Federal de Santa Catarina, Florianópolis, 2013.

ROSA FILHO, D. S.; MISOCZKY, M. C. Proposta de referencial de análise de políticas públicas fundamentado em relações sociais mediadas pela linguagem, relações de poder e razão prática. In: EnANPAD, 30., 2006, Salvador. Anais... Salvador: ANPAD, 2006. p. 1-16.

SALAMAN, G.; STOREY, J. Understanding enterprise. Organization, v. 15, n. 3, p. 315-323, 2008.

SANTOS, B. S. A crítica da razão indolente: contra o desperdício da experiência. 2. ed. São Paulo: Cortez, 2000.

SAUSSURE, F. Curso de linguística geral. São Paulo: Cultrix, 1987.

SOLÉ, A. Créateurs de mondes: nos possibles, nos impossibles. Paris: Rocher, 2000.

¿Qué es una empresa? Construcción de un idealtipo transdisciplinario. Paris: [s.n], 2004. Não publicado.

L'entreprisation du monde. In: CHAIZE, J.; TORRES, F. Repenser l'entreprise: saisir ce qui commence, vingt regards sur une idée neuve. Paris: Le Cherche Midi, 2008. p. 27-54.

THOMPSON, J. B. Ideologia e cultura moderna: teoria social crítica na era dos meios de comunicação de massa. Petrópolis, RJ: Vozes, 2009.

VAN DIJK, T. A. Principles of critical discourse analysis. Discourse \& Society, v. 4, n. 2, p 249-283, abr. 1993.

WACQUANT, L. O legado sociológico de Pierre Bourdieu: duas dimensões e uma nota pessoal. Revista de Sociologia e Política, n. 19, p. 95-110, nov. 2002.

WITTGENSTEIN, L. J. J. Investigações filosóficas. São Paulo: Nova Cultura, 1996. 